\section{The journal I would like}

\author{
Ersilia Vita Fiscarelli \\ 'Bambino Gesù' Paediatric Hospital, Rome, Italy
}

Scientific journals have always played a fundamental role in the dissemination of knowledge in any disciplinary field. The identity of a scientific association is also represented and strengthened by its own journal. Microbiologia Medica (Medical Microbiology; MM), official organ of the Italian Clinical Microbiology Association (AMCLI), for being the expression of a large professional association, actually represents a particularly significant dissemination tool in the diversified editorial landscape of Italian microbiology. It is a quarterly journal, available in electronic format on the website www.microbiologiamedica.it, that can be consulted by the Members in the Reserved Area and is essentially intended for training and information.

The main activities of the journal concern publication of scientific articles (revisions, original articles, manuscripts, clinical cases) in the field of clinical microbiology, with the aim of promoting its members' constant updating and favouring dissemination of new knowledge in the scientific community, thus contributing to a basic learning that supports applied research and technology advancement.

The purpose of the journal is to involve all the members as much as possible and solicit the attention of both readers and authors. With the aim of promoting participation and interest in the proposed topics, in March 2018 the cognitive survey "The journal that I would like" was promoted among AMCLI members with the intent of investigating the members' opinion on specific issues reported on a 9 multiple-answer questions questionnaire (Supplementary Material). It was sent online to 1,296 AMCLI members. Each question required a maximum of 2 answers:

Correspondence: Ersilia Vita Fiscarelli, Ospedale Pediatrico Bambino Gesù, Piazza di Sant'Onofrio 4, 00165 Roma (RM), Italia.

E-mail: evita.fiscarelli@opbg.net

Key words: Microbiologia Medica, Medical Microbiology, AMCLI, questionnaire.

Conflict of interest: the author declares no potential conflict of interest.

Funding: none.

Received for publication: 5 April 2019

Accepted for publication: 10 April 2019.

(C) Copyright E.V. Fiscarelli, 2019

Licensee PAGEPress, Italy

Microbiologia Medica 2019; 34:8203

doi:10.4081/mm.2019.8203

This article is distributed under the terms of the Creative Commons Attribution Noncommercial License (by-nc 4.0) which permits any noncommercial use, distribution, and reproduction in any medium, provided the original author(s) and source are credited.
$29.7 \%$ of the members have joined the survey by properly completing the questionnaire.

A brief summary of the members' opinions reports an almost unanimous (98.6\%) consensus on the fact that articles published in on-line scientific journals and residential practical courses are the most useful tools for a professional updating in real time, although about $1 / 3$ of the participants in the survey (36\%) highlighted that conferences and congresses also play an important role.

Only $4 \%$ of microbiologists read all the articles published on MM, or simply browse the journal; more than $85 \%$ of subscribers read only the articles of their interest. In general, the topics covered provide new knowledge that can be implemented in the clinical practice (52\%), although not everyone (39\%) has the chance to do it and/or the right tools.

Exactly half (50\%) of the microbiologists who answered the questionnaire had previously published on MM, especially original articles (61\%) and case reports (44\%); however, the fact that the journal is not indexed represents the main reason why $59 \%$ of microbiologists submitted their papers for publication to other journals. Furthermore, $36 \%$ of participants (about $1 / 3$ ) reported to have never written an article, although would like to do it, and $12 \%$ believe that having publications in the $\mathrm{CV}$ does not improve their professional role.

Scientific papers may be submitted indifferently in English or Italian. In fact, the survey shows an equal percentage $(50 \%)$ between the two languages. However, the majority of microbiologists $(81 \%)$ who replied to the questionnaire, believe that MM should mainly publish Procedures, Protocols, Recommendations and Guidelines while, to a lesser extent, original Articles (40\%), Monographs (35\%) and case reports (33\%). All of the microbiologists agree on a column titled "The expert answers".

Almost 50 clinical microbiology services operate in Italy (as reported by P. Clerici, President of AMCLI), different for technical-organizational complexity and also for microbiologists' professional qualification.

The results of this survey, aimed at investigating the editorial needs of AMCLI members, provide a picture of a "microbiological world" with diversified editorial requirements.

The survey has reported the shared opinion that our journal should publish Guidelines, Procedures, Protocols and Recommendations, as a useful communication tool that promotes professional knowledge, competences and clinical-technical skills for a constant updating. In particular, it has highlighted the importance of professional trainings, as well as the need for microbiologists to consider the core competence as a basic requirement for quality microbiological diagnostics and, therefore, for patient

The survey has also indicated that about $1 / 3$ of the participants (36\%) has never published in scientific journals, not only because few of them $(12 \%)$ have had a professional benefit from publications, but also because they believe not to be adequately trained to write a scientific manuscript. This last consideration deserves a 
particular attention. Writing is more difficult than all the other forms of communication, where voice and gestures can emphasize or minimize the content.

No doubt that we all do not have the same natural gift for writing. Some have an innate talent for choosing the right words and efficaciously constructing a sentence. Probably, the ability to narrate in writing is part of the genetic heritage of each of us. However, the art of writing, like any other art, can be taught; the basic method can be learned and a person's writing skills can be improved. The Health Professionals Associations, such as AMCLI, which have the mission to support all the scientific activities of its subscribers, should recognize this demand and reconsider training strategies specifically oriented in this direction.

The new communication channels presently available, if properly used, can be extraordinary tools for cultivating and intensifying relations and cultural exchanges. As the Editor in Chief of the journal, I undertake to develop and consolidate this purpose. I therefore invite my microbiologist colleagues, especially young people who wish to approach scientific writing, but fear failures, to use Medical Microbiology as a "gym", where to train themselves to the use of words. How can they achieve this goal? Writing, submitting, reviewing, publishing. 